\section{Кристияна Симеонова}

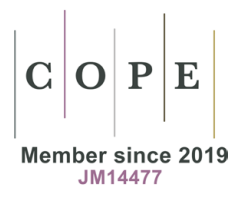

(iD) https://orcid.org/0000-0002-9161-853X

Институт болгарского языка

Болгарская академия наук

София, 1113, бул. „Шипченски проход” № 52, бл. 17

k.simeonova@ibl.bas.bg

\title{
Современный болгарский и русский политический дискурс - тенденции, сходства, закономерности
}

\author{
Modern Bulgarian and Russian \\ Political Discourse - Trends, Similarities, Patterns
}

\begin{abstract}
Резюме
Данный доклад посвящен некоторым интересным языковым явлениям, которые наблюдаются сегодня в болгарском и русском общественно-политическом дискурсе. Эти явления имеют сходный характер, который объясняется сходным характером некоторых политических и экономических процессов в обеих странах. Такими типичными для обоих языков явлениями являются растущая обусловленность общественно-политической лексики экстралингвистическими факторами, вхождение в эту лексику более раскрепощенного, более экспрессивного и более образного языка, выход из активного употребления части лексики, связанной с периодом социализма и др. Автор рассматривает интересные примеры, эксцерпированные в основном из российских средств массовой информации, которые иллюстрируют эти явления. Основным выводом настоящего исследования является то, что сегодняшние тенденции и явления в болгарском и русском общественно-политическом дискурсе имеют сходный характер. Конечно, это не нетипично, когда речь идет о двух генетически связанных и родственных языках.
\end{abstract}

Ключевые слова: сопоставительное исследование, общественно-политический дискурс, идеология, экстралингвистические факторы, метафора.

\section{Summary}

The paper is devoted to some interesting language phenomena occurring today in the Bulgarian and Russian socio-political vocabulary. These phenomena are of a similar nature, which can be attributed to the similar nature of some political and economic processes in the two countries. Such phenomena typical of both languages are manifested in a growing influence exerted on the socio-political vocabulary by extra-linguistic factors, emergence of an increasingly expressive language, 
eradication of part of the vocabulary related to the period of socialism from active use, and others. The author points to many interesting examples, taken mostly from the Russian mass-media, to illustrate these phenomena. The main conclusion of the study is that today's trends and phenomena in the Bulgarian and Russian socio-political discourse are of a similar nature. Certainly, this should not come as a surprise given the genetical relationships between the two languages.

Keywords: comparative study, socio-political discourse, ideology, extralinguistic factors, metaphor.

\section{ВВЕДЕНИЕ}

Общеизвестным является факт, что язык как общественное явление не может оставаться равнодушным и незатронутым тем, что происходит в жизни общества. Наоборот! Коренные изменения в общественно-политической, экономической и социальной жизни неизбежно находят свое отражение в языке и, прежде всего, в лексике, поскольку она наиболее быстро и остро реагирует на эти изменения, отражая их новыми лексическими и фразеологическими единицами. Любое радикальное изменение условий, в которых живут носители данного языка, находит наиболее полное отражение в основном в области общественно-политической лексики, которая меняется с интенсивностью, зависящей от величины изменений в политической и экономической обстановке. Чем крупнее и радикальнее изменения в социально-политической и экономической сфере, тем больше они и в общественно-политической лексике.

Цель настоящей статьи - проследить некоторые из наиболее важных тенденций развития современного болгарского и русского общественно-политического дискурса. Сформулированная таким образом цель объективно предполагает использование синхронного подхода, который изучает и описывает языковую систему только в течение определенного конкретного периода ее существования (в данном случае речь идет о современном периоде). Благодаря синхронному подходу языковые явления рассматриваются вдоль оси одновременности. Основным научным методом, который я буду использовать в этом исследовании, является компаративный (сравнительный), с помощью которого я изучаю зарегистрированные в двух языках соответствия. Научное сравнение языков помогает нам лучше понять некоторые похожие языковые процессы, существующие в двух или более языках. Кроме того, при проведении некоторых анализов неизбежно появляются элементы когнитивизма. Происходит это потому, что политическая лексика напрямую отражает связь человека с обществом и временем, в котором он живет. В связи с этим речь идет не только об отражении объективной действительности, но 
и о выражении жизненного опыта, концептуализации мира, определенных понятий, взглядов, эмоций, психических установок, восприятий, ценностей, оценочных моментов и т. д.

\section{ИЗЛОЖЕНИЕ}

Вопрос о самых характерных явлениях, происходящих сегодня в болгарском и русском политических дискурсах, чрезвычайно обширен и не может быть исчерпан в рамках короткого изложения. Здесь я попытаюсь остановиться только на самых важных из них. Современная политическая лексика болгарского и русского языка отражает на лингвистическом уровне динамические и крупные изменения, наступившие в общественно-политической, экономической и социальной жизни в обеих странах и во всем мире за последние двадцать лет.

1. Из наиболее характерных явлений в болгарской и русской политической лексике я прежде всего упомяну об усилении процесса неологизации. Наша современность характеризуется значительными изменениями в различных областях жизни, с интенсивным развитием науки, компьютерной, информационной и телекоммуникационной технологии, с процессами европейской интеграции, глобализации, рыночной экономики и т.д. В ходе всего этого и с развитием познавательной деятельности человека постоянно появляются новые понятия, которые, как обобщенное отражение реальности в сознании людей, отражают полученные новые знания. В последние годы произошли серьезные, фундаментальные и существенные изменения в общественно-политической, экономической и социальной жизни в Болгарии и в России. Эти изменения, а также глобализация политического мира приводят к появлению новых объектов, явлений, процессов, видов деятельности, организаций, отношений и т. д., И это сопровождается необходимостью называть их. Взаимозависимость между возникающими новыми понятиями и их языковой номинацией через создание соответствующего названия приводит к появлению в языке широкого слоя неологии. Неологизмы называют новые и коммуникативно актуальные понятия. Появляющаяся новая лексическая единица использует словообразовательные возможности языка, в котором она появляется, и строится в соответствии с его нормами. Вопрос о появлении новых слов в языке очень актуальный и дискуссионный. Существует три основные способа: прямое заимствование готовых слов, калькирование и формирование слов средствами родного языка. Еще более сложным является вопрос о том, каким должно быть соотношение между этими тремя способами, должен ли один из них иметь приоритет над други- 
ми, и если да, то какой и в какой степени. Как в болгарском, так и в русском политическом дискурсе, из широко используемых лексических единиц преобладающая часть имеет английское происхождение, что связано с доминирующей ролью англоязычной части мира, с экономическим и технологическим прогрессом англоязычных стран и с распространением англоязычных культур по всему миру. Калькирование также является очень продуктивным способом, на котором я не буду здесь подробно останавливаться.

Также важно подчеркнуть, что неологическая лексика очень динамична и изменчива. Она состоит из единиц, которые имеют разные судьбы с точки зрения их дальнейшего существования в лексической системе. Некоторые неологизмы утверждают себя как полноценные единицы языка. Другая часть, однако, отпадает от языка после периода активного использования. Основной причиной этого является отмирание или деактуализация их понятий и явлений. Это так называемые однодневные слова.

2. Другое очень характерное явление в современном болгарском и русском политическом дискурсе - интернационализация. Использование новой международной лексики в эпоху глобализации в последние двадцать лет как в болгарском, так и в русском языке расширяется. По словам М. Поповой, «интернационализм - это лингвистическая единица, принадлежащая международному языковому фонду» (Попова, 2012, 419). Интернационализмами могут быть не только слова, но и все языковые единицы от морфемы до синтактической конструкции. Опять же, по словам М. Поповой, «интернационализм должен соответствовать двум условиям - одинаковым или сходным значениям и принадлежать как минимум трем языкам, два из которых принадлежат к разным языковым семействам» (Попова, 2012). Например, интернационализмы - это слова, используемые в политической, культурной и научной областях, таких как политика, партия, демократия, диктатура, республика, монархия, конституциия, циивилзация, прогресс, пропаганда, революция, плюрализм и многие другие. Большую часть международного культурного слоя составляют слова, которые происходят от классических языков латинского и древнегреческого. Это относится не только к словам, но и ко многим международным аффиксам и аффиксоидам (например, суффиксы -ucm, -aнm, -изм, -тор, -лог, -ащчия, -изация и т. д.; префиксы и префиксоиды анти-, архи-, мульти-, ультра-, гипер-, мини-, про-, противо-, псевдо-, квази-, ре-, транс- и т. д.).

3. Очень характерна для болгарского и русского политического дискурса - прямая связь с идеологией. Идеология представляет собой очень сложный общественный феномен. Как система определенных политических, философских и др. взглядов, идей, представлений и понятий, присущих определенной партии, классу или социальной группе, идеология является отражением общественного, политического и экономического строя определенной эпохи. Этот факт находит свое лингвистическое выражение в идеологизированности политической терминологии, учитывая то обстоятельство, что 
идеологически релевантными являются только те термины, которые возникли в результате идеологического переосмысления реальности. Ряд философских и общенаучных терминов, которые входят в состав политической терминологии, не идеологизированы (Крючкова, 1989, 15). Интерес вызывает тот факт, что русский исследователь Т. Крючкова говорит о так называемой потенциальной идеологизированности. Под этим она понимает, что в определенных контекстах и при определенных ситуациях чуть ли не любое идеологически нейтральное слово может получить идеологическую окраску (Крючкова, 1989, 17). Также интересно то, что идеологическое значение многих терминов может меняться в разные исторические периоды в следующих основных направлениях: идеологически нейтральные термины идеологизируются (например, демонтаж, перестройка, аннексия, интервенция, ассимиляция, плутократия и т. д.); идеологически релевантные термины деидеологизируются (например, агрессия, саботаж, реакиия, пятилетка, аристократия, буржуазия, фабрикант, коллективизация, капитализм, бизнес и т. д.); и так называемая вторичная идеологизация, при которой идеологический термин интерпретируется снова как идеологический, но с другим звучанием и в системе различных политических взглядов. (Например, часmная собственность, демократия, револючия, полиция, рыночная экономика и т. д.). Эти слова называются полиидеологические идеологемы. Я приведу следующие примеры. В толковых словарях болгарского языка слово демонтаж упоминается как слово нейтрального значения - разборка машины или другого оборудования из ее компонентов или отсоединение детали от системь (например демонтаж автомобильного двигателя). После демократических изменений это слово приобретает политический смысл - разложение и удаление определенных политических структур. Например, демонтаж командно-административной системы социализма. Это слово было использовано в Заключительном докладе Пленума ЦК Болгарской коммунистической партии, который состоялся 10 ноября 1989 года. Как отмечает Л. Йорданова, «с помощью средств массовой информации это слово очень быстро активируется в языке в политическом употреблении и даже приобретает с ним словообразовательную активность (например, монтажники и демонтажники социализма, демонтаж социилизма, демонтаж старой системы и т.д» (Йорданова, 1993, 13). Другой пример: раньше в русском языке слово перестройка не имело политического смысла. Это означало только реорганизацию. В 80-ах годах $\mathrm{XX}$ века это слово приобретает политический смысл в значении процесс различных реформ, начатых в середине 80-х годов в Советском союзе советским лидером М. Горбачевым, иелью которых, вообще говоря, является примирение социализма и демократии.

4. Очень важным и характерным процессом в современном болгарском политическом дискурсе является выход из активного употребления части лексики, связанной с периодом социализма, из-за исчезновения или де- 
актуализации понятий, которые она означает. Например, такие понятия, как ленински съботник, преходно червено знаме, колхоз, совхоз, комсомол, чавдарче, стахановеч, агитпропотдел, отечественофронтовец, пролетарий и др. не понятны самому молодому поколению. Однако другая часть появившейся во время социализма лексики не вышла из активного употребления и известна даже самым молодым. К примеру, партиен секретар, централен комитет, стенвестник, орденоносеи, ударник, народна власт, социалистическа револючия, политическа пропаганда, идеологическа диверсия и др. На это интересное явление обращают внимание болгарские исследователи Л. Крумова-Цветкова и Д. Благоева. По мнению Л. Крумовой-Цветковой, «эта лексика не устаревшая, а устаревающая, так как при ней процесс старения во многих случаях еще не закончился» (Крумова-Цветкова, 2009, 366). Д. Благоева отмечает, что «однако, когда речь идет о лексике близкого переходного периода, нередко наблюдается неравномерность в деактуализационных процессах. Это означает, что возможно, чтобы лексические единицы, деактуализованные для лингвистического сознания определенных социальных групп, оставались в силе для других частей общества» (Благоева, 2012, 133).

5. Для сегодняшней болгарской и русской политической речи характерным признаком является ее усиленная обусловленность экстралингвистическими факторами. В сфере политики и в Болгарии, и в России наблюдается вербальная коммуникация как между политическими субъектами в рамках самой политической системы, так и между ними, с одной стороны, и остальной частью общества, с другой. Очень существенным моментом является то, что при этой коммуникации целью является не только предоставление информации, но и воздействие на зрителей или слушателей, формирование или изменение определенных убеждений, взглядов, ориентаций и пр. Это определяет все более полное проникновение в болгарский и в русский политический дискурс раскрепощенного языка, экспрессивного заряда, образности и эмоциональности высказывания с целью достижения более крупного и более яркого воздействия на слушателей. Все это вписывается в сегодняшние процессы общей демократизации языка. Однако эта демократизация была в какой-то степени неправильно воспринята как вседозволенность. В официальный политический устный дискурс и в язык печатных и электронных СМИ вторглись элементы просторечия, жаргонизмы, вульгаризмы и даже, к сожалению, цинизмы. Конечно, мы не можем оправдать этот способ формального выступления, даже из-за аргумента, что язык, как общественное явление является зеркалом общества, следуя за общественным развитием, и вседозволенность во всех сферах общественной жизни логически также наблюдается и в языке. Сегодня в значительной степени ослабевают и расходятся строгие и четкие границы, которые в прошлом отделяли официальное общение от неофициального. Кроме того, из-за своего своеобразного (a, может быть, и неправильного) понимания свободы слова почти 
отсутствует самоконтроль у говорящих за их собственной речью. Сегодня в официальных публичных выступлениях наблюдается сильное увеличение употребления элементов низкого стиля (т. е. разговорных, жаргонных, вульгарных и др. слов). Для того, чтобы нейтрализовать сухую и скучную книжную официальность из недавнего прошлого, сегодняшняя политическая речь сознательно ищет свежее, колоритное и красочное речевое поведение, потому что такое поведение очень выразительно и увлекательно для народных масс, оно заражает своей непринужденностью. Эти языковые средства очень привлекательны для выполнения стилепонижающей и экспрессивной функции. Игнорируя строгие и в некоторой степени искусственные нормы и правила политической речи, существовавшие во время социализма, политики, министры и депутаты, возможно, стремятся сократить дистанцию между собой и избирателями, показать свою близость к народу, быть ясными и понятными для простых людей. Несмотря на это, однако, стилистическое снижение и сильное влияние просторечной речи в политическом дискурсе болгарского и русского обществ, по всей вероятности, уже перешли предельно допустимые границы. Не только в Болгарии, но и в России, речевая деятельность многих современных политиков и журналистов вызывает тревогу у болгарских и русских лингвистических обществ, а также у общества в целом. Сегодня едва ли не постоянной рубрикой во многих авторитетных русских средствах массовой информации, как «Литературная газета», «Комсомольская правда», «Аргументы и факты», «Итоги» и т.д. стала публикация т. н. «жемчужин» речевой деятельности политиков и журналистов. Я позволю себе указать на интересный факт. Валентина Ивановна Матвиенко (российский политик, которая в 1998 году стала заместителем председателя Правительства Российской Федерации и оставалась на этом посту до 2003 года, a c 21 сентября 2011 года является председателем Совета Федерации России) в своем интервью рассказывает, что более полугода пыталась отучить одного из высокопоставленных государственных чиновников от употребления грубой и просторечной лексики во время заседаний правительства. «Я добилась весьма скромных успехов» - был ее вывод. Интервью было дано газете «Комсомольская правда» в ноябре 2000 года. Беспокойство в российском обществе по этой теме настолько велико, что в 1994 году выходит книга Культура парламентской речи, а в 2010 году вышло третье переработанное и дополненное издание книги Не говори шершавым языком.

Как уже было упомянуто, в настоящее время и в Болгарии, и в России есть стремление, чтобы в политическую речь вошли раскрепощенный язык, экспрессивный заряд, образность и эмоциональность высказывания. Одним из наиболее часто используемых в обоих языках способов для всего этого является расширение употребления метафор, метонимий, фразеологических словосочетаний, устойчивых сравнений и т. д. Русский исследователь Анатолий Прокопьевич Чудинов говорит: 
Метафоричность - один из важнейших признаков современной русской агитационно-политической речи... Метафорические модели ярко отражают современные представления о российской действительности и языковый вкус эпохи...В метафорическом зеркале отражаются мировосприятие граждан России, их представления о специфике современного этапа экономического и политического развития страны, их отношение к властным структурам и оппозиции, к политической деятельности и новым условиям жизни, их реакция на важнейшие события в жизни государства (Чудинов, 2001).

Приведу несколько примеров, иллюстрирующих употребление метафор, метонимий, фразеологизмов и устойчивых сравнений в русском политическом дискурсе. «Финансовый кризис дал депутатам серьезный шанс попробовать на зуб прочность президентской власти» (отрывок из публицистической передачи по «Первому каналу»); «Нашей партии нет необходимости прятаться за чью-то спину» (отрывок из выступления Вл. Жириновского); «Многие голосуют ногами, то есть попросту, не ходят на выборы»; «Кавказ давно уже называют ахиллесовой пятой России»; «Еще с лета 1990 г. Россия начала переговорный процесс с другими союзными республиками о мирном, нежном разводе» (последние примеры - из русской печати); «Избранный президент и страна - как жених и невеста, инаугурация - как вступление в брак, а последующий период - как медовой месяц» (отрывок из публицистической передачи по «Первому каналу») и т.д. Другие, часто употребляемые в сегодняшнем русском политическом дискурсе метафорические выражения, имеющие соответствия в болгарском языке: удар ниже пояса (использование незаконных средств в политической борьбе), получить красную карточку (в случаях, когда политик теряет поддержку и доверие избирателей и пр.), хамелеон меняет окраску (о политике, который часто меняет свои взгляды с целью остаться у власти), страус прячет голову под крыло (когда кто-то не хочет узнать неприятную для него правду), косметический ремонт (о незначительных, несущественных и ничтожных реформах), камень преткновения (о препятствии, затруднении) и др. Яркую образность придают языку такие словосочетания, как нужен, как рыбе зонтик (или как прошлогодний снег), вертеться (или крутиться), как береста на огне, жить (или чувствовать себя), как на вулкане, (за)путаться, как муха в паутине и т. д.

\section{ВЫВОДЫ}

Основным выводом настоящего исследования является то, что сегодняшние тенденции и явления в болгарском и русском общественно-политическом дискурсе имеют сходный характер, который объясняется, с одной стороны, некоторыми сходными политическими и экономически- 
ми процессами в обеих странах, а с другой - некоторыми общими чертами и направлениями в развитии самих языков, которые ведут к специфическому способу письменного и устного выражения, сформировавшемуся в рамках данной институциональной сферы, в данном случае политики.

Конечно, это не нетипично, когда речь идет о двух генетически связанных и родственных языках. Сопоставительное рассмотрение данных явлений способствует их более глубокому изучению и познанию. В этом отношении болгарский и русский языки - эти великие и богатые славянские языки, предлагают нам еще много вопросов, открытых для будущих исследований.

\section{БИБЛИОГРАФИЯ}

Благоева, Д. (2012). Актуални проиеси в българската обществено-политическа лексика. В: сборник Магията на думите, (129-146), Д. Благоева, С. Колковска (ред.), София: Академично издателство Проф. М. Дринов.

Йорданова, Л. (1993). Езикът на промяната. София: изд. „Буллекс”.

Крумова-Цветкова, Л. (2009). Остаряващци думи, значения и форми в съвременния български книжовен език. В: Сборник Езиковедски изследвания в чест на чл.-кор. проф. д-р T. Бояджиев, проф. д-р В. Попова и проф. П. Пашов. София: Университетско издателство Св. Кл. Охридски.

Крючкова, Т.Б. (1989). Особенности формирования и развития общественно-политической лексики и терминологии. Москва: Издательство «Наука».

Попова, М. (2012). Теория на терминологията. Велико Тьрново: ИК „Знак 94”.

Чудинов, А.П. (2001). Россия в метафорическом зеркале: когнитивное исследование политической метафоры. Екатеринбург - По: http://philology.ru/linguistics 2/chudinov_01.htm (доступ 20.03.2020).

\section{$* * *$}

Blagoeva, D. (2012). Aktualni protsesi v b"lgarskata obshchestveno-politicheska leksika. V: sbornik Magiyata na dumite, (129-146), D. Blagoeva, S. Kolkovska (red.), Sofiya: Akademichno izdatelstvo Prof. M. Drinov.

Chudinov, A.P. (2001). Rossiya v metaforicheskom zerkale: kognitivnoe issledovanie politicheskoi metafory. Yekaterinburg - Po: http://philology.ru/linguistics 2/chudinov_01.htm (dostup 20.03.2020).

Iordanova, L. (1993). Ezik”t na promyanata. Sofiya: izd. „Bulleks”.

Krumova-Tsvetkova, L. (2009). Ostaryavashchi dumi, znacheniya i formi v s"vremenniya b"lgarski knizhoven ezik. V: sbornik Ezikovedski izsledvaniya v chest na chl.-kor. prof. d-r T. Boyadzhiev, prof. d-r V. Popova i prof. P. Pashov. Sofiya: Universitetsko izdatelstvo Sv. Kl. Okhridski.

Kryuchkova, T.B. (1989). Osobennosti formirovaniya i razvitiya obshchestvenno-politicheskoi leksiki i terminologii. Moscow: Izdatel'stvo Nauka.

Popova, M. (2012). Teoriya na terminologiyata. Veliko Tyrnovo: IK „Znak 94”. 